\title{
INTERSECÇÕES ENTRE IDEOLOGIAS LINGUÍSTICAS E RACIOLINGUÍSTICAS NA MANUTENÇÃO DE HIERARQUIAS RACIAIS
}

\author{
INTERSECTIONS BETWEEN LINGUISTIC AND RACIOLINGUISTIC IDEOLOGIES IN THE \\ MAINTENANCE OF RACIAL HIERARCHIES
}

\section{Thaís Elizabeth Pereira Batista*}

\begin{abstract}
RESUMO
Este artigo discute teoricamente intersecções entre noções de raça e língua em sociedades racializadas devido ao violento processo de colonização europeia nas Américas, como o Brasil. Essa racialização subalterniza corpos em detrimento de outros considerados universais e não racializados: homem, branco, europeu, heterossexual. Contudo, considero aqui que todos os corpos são racializados, pois este é um marcador de diferença que gera desigualdades sociais. Partindo da perspectiva decolonial (MIGNOLO, 2003; LUGONES, 2014), que destaca a importância de considerar a diferença colonial como espaço físico e imaginário onde emerge e atua a colonialidade do poder, a exposição será sobre os conceitos de ideologias linguísticas (BAUMAN; BRIGGS, 2000; BLOMMAERT; VERSCHUEREN, 1998; KROSKRITY, 2004; IRVINE, 1989), e como tais ideologias são mobilizadas para justificar hierarquias raciais impostas na sociedade (PINTO, 2014; 2018; ROSA; FLORES, 2017; ROSA, 2019; NASCIMENTO, 2019), atendendo a um projeto de nação colonial hegemônico, advindo da modernidade, centrado na tríade: uma nação, um povo, uma língua. Tal projeto moderno colonial nega a existência de outras cosmologias e ontologias, como um mecanismo de controle dos corpos. Finalmente, apresento estudos que partem do pensamento liminar, no sentido atribuído por Mignolo (2003), indicando saídas contra-hegemônicas e processos de contra colonização, conforme hooks (2008); Bispo dos Santos (2015) e outras/os que partem desse lugar historicamente subalternizado para desestabilizar a tradição colonial acadêmica. Assim, farei uma reflexão sobre a importância da produção do conhecimento gerado por acadêmicas/os indígenas e quilombolas visando à retomada de suas histórias, lutando contra desigualdades que têm sido justificadas pela história única (ADICHIE, 2019).
\end{abstract}

Palavras-chave: ideologias linguísticas; raciolinguística; hierarquias raciais; colonialidade do poder; contra colonização.

\section{ABSTRACT}

This paper makes a theoretical discussion about the intersections between notions of race and language in racialized societies because of the violent process of european colonization in the Americas, such as Brazil. This racialization subordinates bodies to the detriment of others considered universal and not racialized: white man, european, heterosexual. However, I consider here that all bodies are racialized, as this is a mark of difference that generates social inequalities. Starting from the decolonial perspective (MIGNOLO, 2003; LUGONES, 2014), which highlights the importance of considering the colonial difference as a physical and imaginary space where the coloniality of power emerges and operates, the exhibition will focus on the concepts of linguistic ideologies (BAUMAN; BRIGGS, 2000; BLOMMAERT; VERSCHUEREN, 1998; KROSKRITY, 2004; IRVINE, 1989) and how such ideologies are mobilized to justify racial hierarchies imposed on society (PINTO, 2014; 2018; ROSA; FLORES, 2017; ROSA, 2019; NASCIMENTO, 2019), serving a hegemonic colonial nation project, arising from modernity, centered on the triad: one nation, one people, one language. Such a modern colonial project denies the existence of other cosmologies and ontologies, as a mechanism for controlling bodies. Finally, I present studies that start from border thinking, in the Mignolo (2003) sense, indicating counter-hegemonic solutions and processes of counter colonization, according to hooks (2008); Bispo dos Santos (2015) and others who leave this historically subordinate place to destabilize the academic colonial tradition. Thereby, I will think about the importance of knowledge production generated by academic indigenous and quilombolas aiming at the resumption of their stories, fighting against inequalities that have been justified by the single story (ADICHIE, 2019).

Keywords: language ideologies; raciolinguistic; racial hierarchies; coloniality of power; counter colonization.

\section{CONCEPÇÕES DE LÍNGUA(GEM) E SUAS ARTICULAÇÕES COM IDEOLOGIAS E HIERARQUIAS DE PODER}

Teorizar sobre língua na contemporaneidade implica pensar nas relações que se dão diante da complexidade que se instaura no sistema-mundo globalizado no qual vivemos e estabelecemos nossas interações. Por isso, é importante pensar nos efeitos da globalização no sistema-mundo moderno-colonial (WALLERSTEIN, 1974).

Assim, conforme aponta Mignolo (2003), ainda que partamos da compreensão de Wallerstein (1974) sobre a emergência do capitalismo no sistema-mundo, é de suma importância compreender a diferença colonial quando nos referimos a países com histórico de colonização e escravização de pessoas, como é o caso do Brasil.

\footnotetext{
* Doutoranda na Universidade Federal de Goiás (UFG), Goiânia, GO, Brasil. thaiselizpbatista@gmail.com

Orcid: https://orcid.org/0000-0003-3439-8363
} 
A diferença colonial, na concepção de Mignolo (2003, p. 10), é o espaço físico e imaginário onde emerge e atua a colonialidade do poder. "A diferença colonial no/do mundo colonial/moderno é também o lugar onde se articulou o 'ocidentalismo', como imaginário dominante do mundo colonial/moderno". Mignolo distingue o período colonial da colonialidade do poder, pois esta continua viva na forma de colonialidade global. A diferença colonial possibilita a:

classificação do planeta no imaginário colonial/moderno praticada pela colonialidade do poder, uma energia e um maquinário que transformam diferenças em valores. Se o racismo é a matriz que permeia todos os domínios do imaginário do sistema mundial colonial/ moderno, 'ocidentalismo' é a metáfora sobranceira, construída e reconstruída pelas muitas mãos pelas quais passaram a história do capitalismo (Arrighi, 1994) e as ideologias em transformação, motivadas pelos conflitos imperiais. (MIGNOLO, 2003, p. 36-37)

Nesse contexto, é importante refletir que língua é um constructo ideológico que vem sendo mobilizado através dos séculos para articular a vida social. Ela é usada para organizar as relações sociais, para formar alianças e para construir as sociedades. Pensar a língua como ideológica não significa dizer que se trata de uma visão distorcida da realidade, mas de diversas formas de pensar e moldar a realidade. Dessa forma, ela é objeto de disputa e conflitos, pois é na língua que os grupos se organizam e disputam poder nas sociedades.

Além disso, é necessário entender que o conceito de língua(gem) não é unívoco e nem está restrito ao meio acadêmico, ele perpassa diferentes concepções, inclusive de outras cosmologias. De acordo com Luciano (2017), para o povo indígena da etnia Baniwa, língua é um meio de comunicação entre os seres e com o mundo, para que o mundo cósmico permaneça em equilíbrio. "A comunicação, a linguagem e o diálogo são, portanto, essencialmente da ordem espiritual e transcendental." (LUCIANO, 2017, p. 296)

Dessa forma, para o povo Baniwa, a linguagem envolve seres humanos vivos ou mortos, a natureza e não humanos, de forma que há uma dimensão material e outra espiritual. E é por isso que para muitos povos indígenas a língua(gem) é o que situa a pessoa no mundo e no meio social, de forma que língua, sociedade e natureza se relacionam intimamente, e é da comunicação eficaz dos entes que estão na natureza que depende sua harmonia. Então, "Pode-se dizer que, segundo algumas mitologias indígenas, o mundo é resultado de um processo contínuo de comunicação dialógica e dialética dos seres criadores e criaturas." [...] (LUCIANO, 2017, p. 298)

Cabe ainda ressaltar a importância vital e simbólica da língua para os povos indígenas, pois é ela que os conecta com o mundo e a natureza. "Assim sendo, a língua é um fenômeno de comunicação sócio-cósmica, de vital importância na relação recíproca entre sociedades humanas e seres não humanos da natureza." (LUCIANO, 2017, p. 299)

Além disso, desde os escritos de Fanon (2008), a língua tem sido teorizada como o primeiro espaço de dominação. No primeiro capítulo do livro "Pele negra, máscaras brancas" o autor se dedica à questão da linguagem, pois para ele, "falar é existir absolutamente para o outro". (FANON, 2008, p. 33) Por esse motivo, o autor defende que os povos colonizados devem tomar posição diante da linguagem.

Já no que concerne à ideologia, seus estudos remontam das tradições filosóficas e antropológicas e eram considerados pela linguística de tradição bloomfieldiana como insignificantes para suas teorias, ou ainda como perniciosos pelo fato de as ideologias serem vistas como algo que atrapalhava a análise de dados primários, que eram considerados como os únicos dados reais passíveis de estudo e interpretação. (WOOLARD, 1998)

No entanto, conforme aponta Woolard (1998), com base em Michael Silverstein, analisar ideologias linguísticas é extremamente importante para conhecer a estrutura linguística, inclusive o autor considera em sua definição do termo o papel da consciência linguística para racionalizar e influenciar tal estrutura da língua. Assim, para Silverstein, as convenções gramaticais não são apenas modelos neutros e arbitrários, mas são construídas por meio de práticas discriminatórias, e um bom exemplo disso é o uso de pronomes genéricos masculinos em algumas línguas, como o "he" no inglês e o "eles" em português, quando se faz uma referência indefinida ou a grupos compostos por pessoas de diferentes gêneros. Por isso, as investigações com foco em ideologias linguísticas são capazes de construir pontes entre teoria linguística e social. Isso porque ideologia tem um importante papel em moldar e influenciar estruturas linguísticas. (KROSKRITY, 2004; WOOLARD, 1998)

Então, se é na língua que as relações acontecem e se sua estrutura é moldada socialmente, a língua é utilizada para marcar as hierarquias impostas por processos históricos de luta e disputas de poder. Em sociedades como a nossa, algumas marcas de diferença como raça, gênero, classe (BRAH, 2006) se interseccionam com língua de modo a produzir e fortalecer essas hierarquias sociais (PINTO, 2015). Além disso, tais marcas de diferença são constantemente construídas e reforçadas na/pela língua, pois é a linguagem que constrói essas relações de diferença. 
No Brasil, podemos observar como as hierarquias raciais em muitos casos se sobrepõem às outras, pois se trata de uma sociedade altamente racializada e racista, um resquício de seu passado colonial.

Dessa forma, as hierarquias raciais são um ponto fundamental para pensar a colonialidade, que subalterniza e exerce controle sobre corpos e línguas, e tais hierarquias podem ser analisadas ao observar interseccionalidades entre categorias de diferença e língua(gem). Como aponta Nascimento (2019), "o sistema perverso de colonialidade, que produziu no Ocidente séculos de escravidão negreira e dizimação dos povos originários de cada lugar onde se colonizava, não se deu fora, mas dentro dos sistemas linguísticos."

É importante observar os contextos em que essas hierarquias são construídas e mantidas. Consideramos o momento atual como inserido em processos intensos de globalização. Trata-se aqui da globalização geocultural na qual os processos capitalistas se intensificaram, aumentando a mobilidade de informações e pessoas. As informações se disseminam mais rapidamente por meio do aumento de disponibilização da internet com o Web 2.0, na década de 1990. Já a mobilidade de pessoas ocorre por meio de fluxos migratórios diversos que variam cada vez mais em termos de motivos, modalidades de migração e o tempo de permanência. Todas essas mudanças têm acontecido de maneira mais rápida e diversa (BLOMMAERT, 2010; 2012). A chamada globalização geocultural, na qual os processos capitalistas se intensificaram, aumentando a mobilidade de informações e pessoas, propagou o colonialismo de maneira global, que reproduz a diferença colonial também em escala global. (MIGNOLO, 2003)

Neste contexto, as interações linguísticas também ocorrem de maneira mais complexa, no entanto, nos deparamos com alguns paradoxos da globalização. Se por um lado ela permite fluxo, movimentos e intercâmbios em velocidades até então não vistas, por outro lado os estados-nação têm contra-atacado para fortalecer suas fronteiras de maneira física e simbólica, como podemos observar nas tendências mundiais de viradas à direita que têm resultado em eleições de governos ultraconservadores pelo voto popular, como foi o caso do Brasil em 2018 e dos Estados Unidos em 2017. Apesar das mudanças nos processos de globalização, há muitas continuidades, principalmente no que se refere à hierarquização de corpos do processo colonial. (HELLER, 2017)

Podemos observar um exemplo evidente disso nos discursos proclamados por representantes do atual governo do Brasil e seus apoiadores. $\mathrm{O}$ atual presidente da república venceu as eleições com um discurso ultraconservador repleto de racismo, machismo, homofobia e xenofobia. Um discurso nacionalista autoritário que se assemelha a de ditadores como Mussolini e Hitler. A todo o momento, impõem-se ideias autoritárias que desconsideram toda a diversidade existente no país e inclusive sua condição de país democrático e laico, como no excerto abaixo que recupera um trecho de um pronunciamento realizado pelo presidente da república em um evento chamado Marcha para Jesus pela família.

[...] PT, PCdoB, PSOL, essa esquerdalha nojenta, falar que o Estado é laico. O Estado é laico, mas eu, Johnny Bravo, sou cristão. Aqui nesse carro e nesse pátio, nós somos cristãos. Respeitamos todas as religiões e até quem não tem religião. Mas a grande maioria do povo brasileiro é cristão. Ponto final. (BRASIL, 2019).

O exemplo apresentado acima ilustra uma ideologia nacionalista já difundida no Brasil, mas que tem se intensificado, que atrela o território ao povo e a uma única raça hegemônica, desconsiderando toda a diversidade racial existente. É comum ainda ver essas afirmações atreladas a um suposto monolinguismo em língua portuguesa no território brasileiro. O total desprezo à diversidade racial e linguística brasileira não é, no entanto, aleatório. O que é colocado no discurso político como um nacionalismo exacerbado é na verdade vivenciado, cotidianamente, em forma de intolerância religiosa, discriminação de gênero, discriminação de LGBTQIA+, e em forma de racismo.

Além disso, é um discurso interessado que busca justificar posicionamentos e ações. Quando o presidente diz que os povos indígenas do Brasil possuem uma porcentagem grande do território nacional considerando o fato de não falarem nossa língua', é possível observar novamente como a ideologia do monolinguismo em língua portuguesa no Brasil é mobilizada para justificar um interesse específico, neste caso, retirar direitos das populações indígenas brasileiras, os povos originários deste país. Da mesma forma, várias ideologias vão se articulando para justificar e autorizar violências, discriminações e retirada de direitos de minorias, e isso pode ocorrer de maneira implícita ou explícita.

1. Aqui me refiro a uma declaração feita pelo presidente da república a respeito da demarcação de terras indígenas no país. A declaração foi: "O índio não faz lobby, não fala a nossa língua e consegue hoje em dia ter 14 por cento do território nacional". Disponível em: https://www. nytimes.com/pt/2020/04/19/world/americas/bolsonaro-brasil-amazonia-indigenas-funai.html. 
Assim, ideologias linguísticas têm sido mobilizadas para manutenção de poder e subalternização de determinados grupos. No Brasil, conforme apresentado acima, um país racializado, as práticas racistas e o racismo estrutural (ALMEIDA, 2019) são mobilizados em parte por ideologias de linguagem de purismo linguístico que associam um povo a uma nação e a uma língua única, não variável, e também por ideologias de diferenciação hierarquizada. Esse tipo de ideologia serve para manter desigualdades de várias ordens e hierarquizar os grupos sociais. Apesar do mito que circula em nossa sociedade de que vivemos em uma democracia racial, podemos observar estudos com base no censo demográfico que atestam a desigualdade racial brasileira.

Entretanto, no que toca às desigualdades raciais, embora estas possam parecer um pouco mais ou um pouco menos acirradas, dependendo do método de identificação aplicado, o fato é que serão intensas de qualquer forma, e sempre no sentido de prejuízo dos pretos e dos pardos, caracterizando o Brasil como uma sociedade racista (OSORIO, 2003, p. 35).

E como apontam Lima e Silva (2020), a academia não está de forma alguma imune a essa estrutura racista na qual a branquitude confere privilégios a si mesma por meio de sua presença massiva e da autorização de discursos e apagamentos de outros.

Como me identifico como uma pesquisadora branca feminista e comprometida com a causa antirracista, tenho consciência de que estou inserida nessa branquitude acadêmica estrutural que gera tais apagamentos, e que possuo muitos privilégios conferidos ao lugar que ocupo. Assim, considero essencial questionar essa estrutura como uma forma, ainda que pequena, de lutar contra ela e evitar contribuir para a manutenção do status quo acadêmico, que tem gerado tantas violências, excluindo tantos corpos e desautorizando seus discursos.

Por isso, concordo com Lima e Silva (2020) no sentido de que são necessárias algumas desobediências a essa estrutura brancocêntrica com o reconhecimento das epistemologias negras que têm disputado espaço com as epistemologias brancas, patriarcais e coloniais que se colocam como "neutras" para manter a estrutura de poder colonial.

Para as autoras, essa postura de desobediência: "nos convoca a derrubar a máscara do silenciamento (KILOMBA, 2019) que define quem tem autorização discursiva, ou seja, o direito à fala, e quem apenas deve estar restrito ao lugar de escuta e de exame". (LIMA; SILVA, 2020)

Como bem adverte bell hooks a teoria é uma forma de compreender e de intervir no mundo. (hooks, 2019) E, de fato, as epistemologias negras não apenas nos oferecem aportes para leitura crítica da realidade, mas também ofertam ferramentas para ação. E, mais, é na academia branca e elitista que a colonialidade [do saber] se mantém viva, pois as universidades continuam mantendo uma estrutura triangular da colonialidade e ignoram as epistemologias outras produzidas desde às margens. (CASTRO-GOMES, 2007) É este academicismo universalmente aceito e brancocentrado que neutraliza as vozes dissidentes. (LIMA $i$ SILVA, 2020)

Na próxima seção será realizada uma breve abordagem sobre os estudos de ideologias linguísticas, buscando apresentar algumas definições que se fazem úteis para a exposição iniciada. Em seguida, serão apresentadas discussões teóricas sobre as intersecções entre ideologias linguísticas e raciolinguísticas dominantes e a instituição de hierarquias raciais em nações racializadas, como é o caso do Brasil. Por fim, serão realizados alguns apontamentos sobre essas intersecções e caminhos contra-hegemônicos que contestem projetos coloniais modernos como forma de contra colonização dos espaços.

\section{IDEOLOGIAS LINGUÍSTICAS}

Para entender como as ideologias linguísticas começam a ser pensadas no campo de estudos, é importante observar como o termo ideologia tem sido compreendido em diferentes momentos históricos. Pretendo, então, apresentar brevemente o percurso histórico do termo ideologia, algumas de suas abordagens, e como foi apreendido pelos estudos linguísticos, se embasando em disciplinas como a antropologia, sociologia e linguística.

O termo ideologia tem adquirido vários sentidos ao longo da história, tendo começado a obter uma conotação negativa no uso que era feito por Napoleão no século XIX (WOOLARD, 1998). Ao pensar no termo como um conceito, podemos recuperar a concepção marxista e daqueles que seguem seu pensamento, em que o termo carrega o sentido de uma falsa consciência, "percepções sistemicamente distorcidas da realidade, mais especificamente da posição de classe."2 Daí, seguem as concepções de

2. Todas as traduções aqui apresentadas são de minha autoria e foram realizadas para este artigo. 
Althusser de "aparelhos ideológicos do Estado"; de Gramsci que pensava a ideologia como hegemonia de uma classe específica; Habermas, com a ideologia como a comunicação distorcida; e Bourdieu, que aponta que "a conversão de ideologias hegemônicas em práticas e ideias 'normais' era rotulada de 'habitus" (BLOMMAERT, 2006, p. 510).

A tradição durkheimiana da sociologia como psicologia coletiva, contemporânea da ideologia alemã, também lida com o conceito como "visões de mudo" e "sistemas de crenças". "Esse conceito de ideologia é frequentemente chamado de conceito total, pois sugere a aceitação de complexos ideacionais-culturais por todos os membros da comunidade" (BLOMMAERT, 2006, p. 510).

A linguagem é ponto central para a compreensão de tal conceito, e Bakhtin e Voloshinov (1981), com base no pensamento marxista, refletem sobre linguagem atrelada à ideologia. As ideias disseminadas pelo círculo de Bakhtin se destacaram por entender a língua como dialógica e considerar que a língua só existe pelo uso que se faz dela, sendo modulada por quem a usa conforme o contexto, que é cultural, ideológico, histórico e social.

Assim, pensando especificamente no campo da linguística e da antropologia linguística, podemos perceber que a abordagem sobre ideologias linguísticas ainda é um campo em construção. Em Woolard (1998) é possível ver o percurso de ideologias linguísticas como campo de investigação ligado à linguística, antropologia, etnografia da fala, linguística de contato, estudos do letramento, estudos históricos, historiográficos e de políticas linguísticas.

Kroskrity (2004) apresenta várias definições de diferentes autoras/es sobre ideologias linguísticas, algumas têm uma visão muito homogênea sobre ideologias dentro de um grupo cultural. A definição de Silverstein (1979) tem sido considerada uma visão importante para os estudos sobre ideologias linguísticas, pois, do ponto de vista da racionalização do uso linguístico, o autor as define como "Conjuntos de crenças sobre a linguagem articuladas pelos usuários como uma racionalização ou justificativa da estrutura e uso percebidos da linguagem" (SILVERSTEIN, 1979, p. 193). Ele enfatiza o papel da consciência linguística na racionalização, o que influencia na estrutura da língua, podendo moldá-la e até promover mudanças estruturais.

Já para Irvine (1989, p. 255), a definição enfatiza o aspecto sociocultural, em que as ideologias são vistas como múltiplas e construídas. Para ela, ideologias linguísticas podem ser definidas como "o sistema cultural (ou subcultural) de ideias sobre as relações sociais e linguísticas, juntamente com sua carga de interesses morais e políticos - que é um fator mediador crucial."

Compartilhando da concepção de Irvine, é importante observar que tais ideologias nunca são neutras ou transparentes, e que por vezes são construídas em estudos linguísticos e na formação linguística para atender a um projeto de nação de herança colonial (WOOLARD, 1998; KROSKRITY, 2004; BLOMMAERT, 2006). De acordo com Woolard (1998, p. 36), com base em Gal (1991), "o significado social das formas de significação nunca pode ser tomado como natural e transparente e sempre deve ser considerado como uma construção cultural". No mesmo sentido, Araújo e Muniz (2016, p. 28) argumentam:

Assim, temos uma concepção de linguagem eminentemente social que nos oferece uma visão de que nada é por acaso na produção de significados e sentidos, pois estes são constantemente atravessados por ideologias, identidades e jogos de poder; não cabe nessa perspectiva uma concepção de linguagem individual ou unívoca. Partir do princípio de que as relações sociais são perpassadas pela linguagem significa que, mesmo na simples ação de se denominar ou denominar o Outro, os sujeitos estão agindo em suas práticas discursivas de forma política, ideológica, socialmente motivada e determinada, susceptíveis, portanto, às questões sociais, filosóficas, ideológicas, e aos contextos nos quais estão inseridos.

A ideia de um falante sociopoliticamente desinteressado, nessa perspectiva, é um mito que serve até mesmo aos projetos de estudos e descrição de língua, que se diziam neutros e científicos, ao passo que nada mais eram do que uma forma de ver e pensar as línguas. (KROSKRITY, 2004)

Assim, nota-se que de um tópico marginalizado, esse conceito tem se tornado central nos estudos sobre linguagem, uma vez que como já observamos, as definições apontam para o papel das ideologias para moldar e influenciar estruturas linguísticas e para atender a diferentes interesses e permear as relações sociais.

Ideologia linguística, como camada metapragmática da língua em uso, nunca é neutra, ao contrário, "é avaliativa, relacional, socialmente posicionada, investida com interesses e objeto para contestação e dominância". (BLOMMAERT, 2006, p. 511) Pois a própria concepção de língua "é resultado de construção ideológica e, portanto, envolve poder, autoridade e controle. Não existe uma língua real "neutra"" (BLOMMAERT, 2006, p. 512) [...]. E conforme aponta Blommaert (2014, p. 67), o poder não deve ser visto apenas como algo ruim, mas sim em seus "aspectos duais". 
Assim, dizemos que a ideologia linguística não é neutra, pois configura como uma camada metapragmática do uso da língua. Essa função metapragmática compreendida com base em Silverstein $(1979 ; 1993)$ e de acordo com Sgnorini (2008, p. 117), "tem função tanto de descrever e avaliar quanto de condicionar e orientar os usos da língua na interação oral ou escrita"

Nesses discursos, a função metapragmática é codificada em nível denotativo nas/pelas estruturas referenciais e predicativas, o que assegura maior grau de explicitação e, como nos casos dos discursos oficiais e científicos, maior visibilidade. E, conforme aponta Silverstein (1993), também nesses discursos estão articuladas as ideologias lingüísticas, de papel relevante na institucionalização de mecanismos sociais de regulamentação, controle e valoração do acesso, produção, consumo e circulação dos recursos lingüísticodiscursivos: são as ideologias lingüísticas, enquanto sistemas culturais de idéias ou crenças encarnadas nas práticas e articuladas pelos falantes em suas racionalizações, justificativas e avaliações de cunho moral e político sobre estrutura e uso linguístico (cf. Silverstein, 1979: 193; Irvine, 1989: 255), que garantem o sentido e a legitimidade dos padrões usuais de diferenciação e hierarquização de formas e usos e que também servem de parâmetro para a inclusão/exclusão de falantes em redes de práticas e instituições. Em conseqüência, os discursos de função metapragmática também assumem papel relevante na encenação, no sentido teatral do termo, do que Silverstein \& Urban (1996) denominam "luta metadiscursiva", ou seja, disputas de natureza política e ideológica na descrição e regulamentação dos usos lingüísticos por grupos e indivíduos diferentemente posicionados em estruturas e redes sociais de poder e autoridade. (SIGNORINI, 2008, p. 119)

Ainda, em resumo, Blommaert (2014, p. 68-69) aponta ideologias linguísticas como "crenças, ideias, visões e percepções sobre linguagem e comunicação", mas não apenas ideacionais, mas sim práticas "no sentido de Bourdieu, referindo-se à práxis marxista mais do que às noções de Mannheim e Durkheim sobre ideologia".

Kroskrity (2004) considera algumas camadas analíticas das ideologias linguísticas que estão parcialmente sobrepostas. Assim, aponta que uma delas é construída para representar os interesses de um grupo social e cultural específico, desvalorizando determinadas variedades pela sua relação com seus falantes. Outra camada analítica importante está fundamentada na experiência social que nunca é uniforme, mas sempre múltipla. Temos também as ideologias linguísticas como forma de mediação entre estruturas sociais e formas de falar. Além disso, elas têm papel na construção de identidades. A formação de identidade nacional ou étnica subordina determinados grupos, pois simboliza uma nação, mas não representa o interesse de grupos considerados minoritários.

Com base no que foi anteriormente apresentado, me alinho principalmente com as concepções de Irvine (1989) por apresentar uma dimensão sociocultural das ideologias linguísticas, pensando-as como ideias sobre relações sociais e linguísticas, o que leva a uma abordagem mais política e traz a questão de não se tratar simplesmente de uma crença, pois está presente nas ideias de todas as pessoas que fazem uso da língua, sendo elas leigas ou linguistas, sendo percebida ou não de maneira consciente. Além disso, também me atento para a definição de Silverstein (1979) sobre o potencial de tais ideias e racionalizações sobre a língua para moldar seu uso e suas estruturas.

É importante ainda ressaltar que muitas das ideologias linguísticas que têm sido hegemônicas no mundo moderno ocidental são baseadas em ideias de colonialidade e atendem a ideais nacionalistas. Um exemplo evidente são ideologias linguísticas gafrocêntricas da escrita como representação da fala, que se assentam nas ideologias da linguagem colonial: a colonização não só de falantes, mas também de suas línguas vernáculas. (WOOLARD, 1998)

Temos também muito presente em nossa sociedade a ideologia da língua padrão de que existem formas padronizadas de cada língua, o que afeta como as pessoas veem as línguas e, além disso, tem influenciado a forma como a própria linguística e a sociolinguística de orientação variacionista têm tratado de forma pouco crítica as questões sociais, partindo muitas vezes de suposições não analisadas sobre a sociedade com a ideia de comunidade, e a concepção da padronização. (MILROY, 2011)

Cabe pensar ainda o quanto a noção de padronização, que permanece ainda em estudos recentes, como mencionei acima, é perniciosa para nossa sociedade, uma vez que projetos de padronização da língua que se baseiam no purismo se unem a outros projetos nacionalistas que são usados para manter a hegemonia de certos grupos privilegiados e subalternizar grupos marginalizados.

Bauman e Briggs (2000) fazem um longo estudo sobre o papel dos textos filosóficos para a construção de ideologias. Os autores mostram como os projetos de John Locke e Herder foram moldados com ideais de purificação linguística e manejados para legitimar desigualdades, usando a própria estrutura da língua para isso. Com isso, alguns povos são deslegitimados ao serem considerados como incapazes ou ainda, na concepção hederiana, como produtores de discurso, mas incapazes de atingir um nível analítico. Tais projetos se assentam em ideais de objetividade científica e se beneficiam de uma armadilha muito usada na Modernidade de apagar os lugares de enunciação para universalizar o discurso. Assim, os discursos hegemônicos apagam o posicionamento que os cria com o objetivo de colocá-los 
como se fossem o "ponto zero do conhecimento", conforme aponta o filósofo Santiago Castro-Gomez. (BAUMAN, BRIGGS, 2000)

Esse tipo de pensamento filosófico contribuiu para moldar um modelo de nação que relega a determinados corpos apenas o papel de informantes ou objetos de estudo, desvalorizando epistemologias e identidades não eurocentradas, como refletem Lima e Silva (2020). Conforme aponta Muniz, esse tipo de concepção atende a interesses de um projeto de nação específico:

Como pensar outras epistemologias se essas identidades continuam relegadas a um lugar de falados, mas não de falantes? Como conceber outras formas de pensar a linguagem e sua relação intrínseca com as identidades dos sujeitos se se considera apenas uma matriz de conhecimento? Até hoje os estudos sociolinguísticos não sabem explicar, com algum consenso, o porquê de não termos crioulo se em mais da metade do que se conhece da história desse país tivemos como população majoritária os africanos, seus descendentes e, obviamente, suas línguas. Que projeto tão radical de extinção e genocídio foi este que apagou esta possibilidade? (MUNIZ, 2016, p. 782)

Por fim, pensando nos apontamentos de Muniz (2016), cabe discutir agora como as ideologias linguísticas têm se interseccionado com marcas de diferença. Aqui darei destaque para a forma como tais ideologias têm sido usadas para justificar e manter hierarquias raciais em nossa sociedade, mantendo determinados grupos e suas práticas como hegemônicos e subalternizando tantos outros grupos e desconsiderando suas diversidades.

\section{LÍNGUA E RAÇA: A RACIOLINGUÍSTICA E SUAS RELAÇÕES COM O RACISMO BRASILEIRO}

Após essa breve explanação sobre o percurso histórico do termo ideologia e sua construção conceitual na relação com língua(gem), levando ao desenvolvimento da noção de ideologias linguísticas, sobretudo no âmbito da antropologia linguística e de outros estudos linguísticos que relacionam língua, sociedade e cultura, inclusive com abordagens etnográficas, quero chamar a atenção para a forma como essas ideologias se constroem para atender a projetos nacionais baseados no pensamento moderno colonial. A tríade um povo, uma nação/território, uma língua: "o cerne da ideologia nacionalista, pensada principalmente por Herder no cenário do Romantismo alemão - tem papel fundamental no uso da linguagem como estratégia de colonização do saber" (OLIVEIRA, 2018, p. 27).

Dessa forma, a diferença colonial se relaciona com as concepções sobre língua, o que deve ser considerado língua e as avaliações que se fazem delas. Em geral, as avaliações feitas sobre o uso da língua e sobre o que pode ser considerado como língua estão diretamente ligadas à posição que ocupam as pessoas que a usam, refletindo totalmente a estrutura colonial de dominação. Assim, são aceitas as línguas de quem historicamente domina, juntamente com a sua produção de conhecimento, ao passo que todas as outras formas de usar a língua ou produzir saberes são desautorizadas pelas estruturas coloniais de poder.

Como mencionei na seção anterior, as principais definições de ideologias linguísticas com as quais me alinho são as de Irvine (1989) que considera o aspecto sociocultural e de Silverstein (1979) que parte da racionalização dos usos linguísticos. A carga moral e política considerada na definição de Irvine (1989) nos mostra que ideologias linguísticas nunca são neutras, e conforme Pinto (2018), tais ideologias no Brasil estão extremamente conectadas às ideologias racistas. Para a autora, a "performance linguística" está menos relacionada com aspectos cognitivos do que com questões ideológicas. Há uma sobreposição entre "natureza racializada das nossas ideologias linguísticas e a natureza linguística das nossas ideologias racistas" (PINTO, 2018, p. 709). Para Nascimento (2019), é importante observar como o "racismo se desdobra através da linguagem e como a linguagem é desdobrada (senão criada ou recriada) através do racismo".

Esse tipo de ideologia vem sendo tradicionalmente construída no mundo moderno colonial com base em projetos de "purificação linguística", desde Locke e Bacon, usados como processos de exclusão para legitimar desigualdades, por meio de hierarquias discursivas que ajudam a criar hierarquias sociais. A língua cria formas de exclusão. Tais projetos, por meio das armadilhas da modernidade, buscam apagar os lugares de enunciação (do branco europeu, da elite) como modo de universalizar uma suposta produção do conhecimento neutra e baseada em verdades irrefutáveis (BAUMAN; BRIGGS, 2000).

Como tenho argumentado até aqui, juntamente com as autoras e autores que trago para a discussão, tais projetos atendem a um modelo moderno colonial eurocentrado que posiciona e hierarquiza corpos em sociedades marcadamente racializadas como a nossa. Essas hierarquias raciais são, muitas vezes, "rarefeitas" (PINTO, 2018) em hierarquias linguísticas que valorizam o mundo branco europeu e as elites colonizadas que com ele se parecem, 
inferiorizando e subalternizando corpos negros e indígenas, por exemplo, considerando suas práticas e usos linguísticos menos legítimos.

Dessa forma, em meio a vários estudos e teorizações que se preocupam com as intersecções entre raça e língua, podemos assinalar o conceito de raciolinguística abordado por Rosa e Flores (2017) e por Rosa (2019), que nos ajuda a observar as discussões sobre como os mecanismos de colonialidade refletem em outra armadilha da modernidade que é instituir um grupo como superior usando-se do argumento de que o grupo subalternizado deve suprir um déficit para alcançar a superioridade. No entanto, como nos apontam diversos/as autores/as (BLOMMAERT; VERSCHUEREN, 1998; ROSA; FLORES, 2017; ROSA, 2019), não importa o que façam ou digam as pessoas subalternizadas por sujeitos racialmente hegemônicos, elas nunca serão consideradas parte daquela elite.

Nascimento (2019), com base nos trabalhos de Flores e Flores (2017), aponta que as políticas de Estado têm sido produzidas como políticas linguísticas de racialização numa perspectiva raciolinguística que se embasa em ideologias raciolinguísticas que veem as "línguas como espaço de purificação e limpeza do projeto colonial".

$\mathrm{Na}$ maioria das vezes, ideologias raciolinguísticas podem se disseminar por meio de interpretações de sujeitos racialmente hegemônicos que são parte de uma semiótica racializada mais ampla e estão ligadas a vários sinais não linguísticos associados a sujeitos racializados, como práticas de letramento, características físicas, comportamento corporal, vestimenta (ROSA; FLORES, 2017). Um exemplo que podemos citar é o fato de sujeitos racialmente hegemônicos usarem constantemente suas interpretações semióticas para justificar atos de violência e racismo contra pessoas negras no Brasil. Pois conforme Sales Junior (2006) nos mostra, vivemos em um país que prega o mito da democracia racial e que propagou a ideologia do "povo mestiço", de uma "nacionalidade morena". Tal ideologia se mostra nas práticas sociais em que há uma cordialidade nas relações raciais, no entanto, o autor aponta que essa cordialidade contribui para manter desigualdades e as hierarquias raciais, uma vez que "A cordialidade não é para 'negros impertinentes'. As relações cordiais são fruto de regras de sociabilidade que estabelecem uma reciprocidade assimétrica que, uma vez rompida, justifica a 'suspensão' do trato amistoso e a adoção de práticas violentas" (SALES JUNIOR, 2006, p. 230).

Isso pode ser observado constantemente nos noticiários quando atos de violência policial ou de civis contra pessoas negras são justificados por supostas semelhanças entre características (físicas, vestimentas, comportamentos) dessas pessoas com a de pessoas criminosas. Não haveria espaço nesta breve explanação para citar o quanto isso acontece no mundo ou mesmo no Brasil. No entanto, destaco o caso ocorrido no ano de 2019, e que teve bastante repercussão na mídia, em que militares fuzilaram o carro de uma família negra na cidade do Rio de Janeiro com mais de 80 tiros, sem sequer abordar seus integrantes antes, e alegaram ter confundido o carro com o de criminosos. (G1, 2019)

Essas práticas racistas são expressas na linguagem de várias maneiras. Muitas vezes são justificadas por meio da introdução de outros elementos como uma suposta aparência suspeita da pessoa negra, ou ainda como aparência inadequada para ocupar certas posições, como apontado por Ferreira (2012, p. 195):

Davis (2000) dá alguns exemplos que demonstram que a polícia e outras autoridades no Brasil usam expressões como "aparência suspeita, cara de ladrão [...] para se referir à presença da população negra" (p. 99). Além disso, até muito recentemente, era comum os anunciantes de empregos solicitarem candidatos de "boa aparência", querendo dizer que não havia a necessidade de a população negra se candidatar. Por conseguinte, o que ocorre é que, em vez de fazer referência a si próprios como negros, afro-brasileiros ou afrodescendentes, a tendência manifestada pelas pessoas é a de tentar retratar a si próprios com diferentes tonalidades de pele, usando tonalidades mais claras, o que sugeriria o embranquecimento. [...]

O que observamos em casos como esses é que práticas racistas não são consideradas aceitáveis publicamente, de forma que são constantemente rarefeitas em outras interpretações semióticas como modo de falar, se vestir ou se comportar. Assim, o racismo muitas vezes se disfarça de padrão linguístico com o objetivo de excluir, punir e desconsiderar corpos não brancos. Considerando práticas linguísticas mais ou menos ideais não com base em suas características em si, mas em como são percebidos raciolinguisticamente os corpos que as usam (ROSA, 2019; PINTO, 2018).

Conforme Pinto (2018, p. 707),

Do mesmo modo, a Modernidade na Linguística se constitui como um gesto violento mitificado como o sacrifício inevitável de pragmáticas e metapragmáticas - formas de falar e existir reduzidas à "superioridade" da metalinguagem "moderna" e "emancipadora" dos estudos científicos das línguas. O sacrifício, claro, tem sido também um sacrifício de corpos e não apenas de modos de falar ou modos de se avaliar a fala. 
Com base no trabalho de Flores (2017) nos Estados Unidos, Nascimento (2019) propõe a adoção de outra lógica raciolinguística, com uma agenda de inclusão. Para isso, é preciso racializar práticas linguísticas que concretizam políticas de exclusão, no caso do Estados Unidos a desigualdade na política migratória, e no caso do Brasil o "colonialismo secular que apaga suas próprias marcas enquanto continua desumanizando e animalizando os corpos negros no país."

Ao tratar sobre o racismo linguístico, Nascimento (2019) nos alerta para o fato de que o preconceito contra o chamado português brasileiro é uma forma de o racismo se materializar em nossa sociedade, de maneira que as elites brancas consideram inadequados os modos de falar que são associados ao Outro, no caso a pessoa negra. Esse preconceito é, na verdade, uma "via do preconceito racial no país, em seu caráter linguístico".

O autor faz referência ao debate já realizado por Gonzalez (1983), quando chama a atenção para o uso do pretoguês como uma língua que traz características de línguas africanas, tendo suas características avaliadas negativamente simplesmente por serem mais presentes nas falas de pessoas negras.

Dessa forma, podemos pensar o chamado modelo icônico de Silverstein (2003) de standartização linguística como uma ligação entre língua, pessoa e lugar hierarquicamente posicionados. Essa hierarquização se constrói a partir da dimensão da percepção: como as pessoas são lidas raciolinguisticamente? (ROSA, 2019)

Segundo Oracy (1985), a marca principal que permite a identificação das potenciais vítimas de preconceito é a cor, para a qual existe uma espécie de escala de gradação que vai do estritamente branco (o nível ideal) ao completamente preto. O preconceito se intensifica na razão direta dessa escala de cor e do porte de outras marcas: quanto mais negra é uma pessoa maior é a probabilidade de ser vítima do preconceito. Em essência, as categorias branca, parda e preta refletem essa escala: são os dois pontos extremos e as posições intermediárias sintetizadas em uma única categoria (OSÓRIO, 2003, p. 22).

O conceito de linguicismo, apresentado por Rosa (2019), demonstra também o racismo. Essa noção corresponde ao remapeamento de raça da onto-língua biológica. Como a inferioridade biológica não foi bem aceita no Brasil, por causa das ideologias de miscigenação (SALES JUNIOR, 2006), então se fala em inferioridade linguística, pois assim atribui-se a inferioridade linguística não às suas características estritas, mas relacionando-as com os corpos que a usam, de modo que inferioridade linguística sempre foi usada como argumento para o racismo brasileiro. Para alguns corpos, por exemplo, o multilinguismo é considerado uma barreira linguística, enquanto para outros é visto como habilidade proveniente de esforço individual e que permite acesso a bens materiais e à ascensão social e ao mercado de trabalho. Isso leva às pessoas não brancas a sentirem-se frustradas com suas habilidades linguísticas a ponto de pensarem não saber nem mesmo a própria língua, enquanto o multilinguismo dos corpos brancos é altamente valorizado. (ROSA, 2019; PINTO, 2014) Isso porque o conhecimento de línguas hegemônicas como o inglês é valorizado, enquanto o conhecimento de outras línguas, como as línguas indígenas, por exemplo, é desvalorizado.

[...] onde vige o preconceito racial de marca, a origem não importa, apenas quantos traços ou marcas do "fenótipo" do grupo discriminado são portados pela vítima potencial. O preconceito racial de marca não exclui completamente, mas desabona suas vítimas. Portar os traços do grupo discriminado constitui inferioridade e faz que os sujeitos ao preconceito sejam sistematicamente preteridos em relação aos demais. (OSÓRIO, 2003, p. 21)

Portanto, podemos observar que no Brasil, assim como em outras sociedades racializadas, as ideologias linguísticas operam para atender a um projeto nacional baseado na ideologia do monolinguismo e em uma suposta identidade nacional que subalterniza de maneira violenta todas as práticas de corpos não brancos por meio de metapragmáticas da língua em uso e têm como consequência fazer com que os subalternizados se sintam sempre estrangeiros, até mesmo em seu próprio território linguístico (PINTO, 2018; ROSA, 2019). Como reflete Muniz (2016, p. 770-771):

Se essa ideia de língua contaminada, impura, maculada pelo exterior a ela tivesse ficado apenas no campo acadêmico, não causaria tantos danos, mas a própria sustentação do que seja ciência linguística se apoia nessa visão na qual a linguagem ordinária, a linguagem que efetivamente utilizamos, é cheia de erros e precisa ser corrigida. Essa visão está presente em nossas escolas e na forma como cotidianamente a maioria dos sujeitos percebe a linguagem. É por isso que não interessa o que o falante leigo reflete sobre a língua, mas apenas o que ele diz na língua para que nós possamos descrever, enquadrar e corrigir imediatamente fazendo com que não se sintam adequados. Se sentir estrangeiro em seu próprio território linguístico parece que vem sendo uma das grandes consequências dessa visão porque apaga completamente nossas errantes existências linguísticas por não se encaixarem em um sistema pronto e acabado que vê a língua como um fato social, apenas no sentido de que é partilhada por uma comunidade linguística específica.

Conforme a reflexão de Muniz (2016) no trecho acima, podemos notar que ideologias de padronização e purismo linguístico têm sido usadas constantemente para apagar as "existências linguísticas" de muitos corpos, 
pois essas ideologias se propagam por várias esferas sociais, produzindo consequências como a estrangeirização de determinados grupos, que inclusive são considerados na produção do conhecimento científico mainstream apenas como objetos de pesquisa, tendo suas próprias reflexões sobre a língua desvalorizadas, uma vez que são vistos como incapazes de produzir conhecimento. Essa discussão será ampliada na próxima seção, na qual será discutido o movimento contra-hegemônico na produção do conhecimento. Conforme Muniz (2016, p. 769), "É possível vislumbrar algumas áreas ou autores que se arvoraram a tarefa de por a Ciência com 'c' maiúsculo para se repensar ou ao menos para ser vista a partir de outras vozes."

\section{PENSAR ALTERNATIVAS CONTRA COLONIAIS}

Como vimos até aqui, diferenças linguísticas são hierarquizadas de maneira que constroem performativamente a hierarquia social (KROSKRITY, 2004) e racial. Assim, como temos visto desde os escritos de Franz Fanon, não importa o que os corpos subalternizados historicamente façam, eles continuarão sendo considerados incapazes e inferiores nos discursos de sujeitos hegemônicos. Mesmo que certos corpos dominem variedades mais valorizadas eles continuarão sendo avaliados de maneira diferente (HELLER, 2017). Isso porque, conforme mencionado na seção anterior, o que vai ser julgado na hora de avaliar são as marcas do corpo que enuncia.

Além disso, conforme aponta Lugones (2014), a Modernidade nega a existência como um mecanismo de controle de corpos. Trata-se de negar a existência de outros mundos ou ontologias. Essa negação é constitutiva da Modernidade e rouba a validade daquilo que tenta negar a existência. "A diferença entre moderno e não moderno torna-se - na perspectiva moderna - uma diferença colonial, uma relação hierárquica na qual o não moderno está subordinado ao moderno." (LUGONES, 2014, p. 943)

É neste contexto que Mignolo destaca a importância de um pensamento liminar como "uma consequência lógica da diferença colonial", e uma reação a essa diferença. (MIGNOLO, 2003, p. 10) Isso porque:

A diferença colonial cria condições para situações dialógicas nas quais se encena, do ponto de vista subalterno, uma enunciação fraturada, como reação ao discurso e à perspectiva hegemônica. Assim, o pensamento liminar é mais que uma enunciação híbrida. É uma enunciação fraturada em situações dialógicas com a cosmologia territorial e hegemônica (isto é, ideologia, perspectiva) (MIGNOLO, 2003, p. 11).

Pensando nessa reação à diferença colonial, podemos falar sobre a importância de teorizar sob o ponto de vista do subalterno quando se fala de produção do conhecimento na América Latina, por exemplo, pois adotar uma postura decolonial, implica repensar o locus enunciativo, buscando resistir a uma produção do conhecimento eurocentrada, que parte sempre do olhar do colonizador para contar as histórias dos povos colonizados.

O longo processo de colonização das Américas, assim como outros processos de colonização no planeta, construiu a Modernidade e a razão Moderna, moldando as concepções das modernidades coloniais ou modernidades subalternas, no período do fim do século XV até o início da globalização, pois "construíram um arcabouço e uma concepção do conhecimento baseado na distinção entre a epistemologia e a hermenêutica e, ao fazê-lo, subalternizaram outros tipos de conhecimento". (MIGNOLO, 2003, p. 36)

No caso do Brasil, uma nação formada a partir dos povos indígenas brasileiros, europeus e africanos, ocorre o apagamento da existência de dois desses grupos constitutivos do país. De acordo com Muniz (2016, p. 781):

Essa construção de nação que apaga as existências, inclusive linguísticas, de dois componentes da história do país tem consequências graves no nosso modo de fazer pesquisa. Não é à toa que esses sujeitos são sempre construídos como objetos de pesquisa tendo suas vozes abafadas pelas nossas bibliografias eurocêntricas e nossa forma de ver o mundo a partir do ocidentalismo.

Por isso, desestabilizar é importante, como nos apontam Lima e Silva (2020) ao propor desobediências no ambiente acadêmico como maneira de romper com a estrutura brancocêntrica. Assim, vários estudos têm mostrado caminhos e alternativas para enfrentar essas hierarquias impostas historicamente, sejam elas raciais, de gênero ou outras. É importante pensar em estratégias contra-hegemônicas para fazer emergir discursos anteriormente desautorizados, invisibilizados e subalternizados.

Borba e Lopes (2018), por exemplo, mostram como a língua é território em disputa, e que tal disputa é de poder, em suas análises sobre desestabilizações linguísticas em escritas no Colégio Pedro II e na UFRRJ, que ao apagar as diferenças de gênero na escrita, como forma de inclusão, geraram grandes polêmicas e práticas de regulação 
linguística. Tal regulação parte de discursos de higiene verbal (CAMERON, 2012), que a autora e o autor contrapõem a uma ideia de imundície verbal, vista como um posicionamento político que desafia imposições históricas de purismo linguístico.

Nesse mesmo caminho, estamos vendo surgir vozes diversas em diferentes espaços, inclusive no ambiente acadêmico que, como vimos, tem sido dominado por elites brancas que muitas das vezes produzem um conhecimento considerado universal partindo de uma perspectiva eurocêntrica, como forma de colonização do saber. (OLIVEIRA, 2018)

Dessa forma, disputam espaço com as vozes hegemônicas, as vozes de autoras e autores representantes de grupos subalternizados, que reivindicam sua própria história, anteriormente contada e analisada sob a perspectiva da colonialidade. Esse posicionamento ajuda a evitar os riscos de uma história única, no sentido atribuído por Adichie (2019), que quando contada da perspectiva do colonizador costuma reduzir a poucos aspectos toda a complexidade de um povo.

São muitos os trabalhos que resultam dessa luta contra-hegemônica pela ocupação dos espaços de produção do conhecimento. Autoras e autores com os quais dialogo neste artigo representam apenas alguns dos nomes de destaque, como Gonzalez, (1983); hooks (1994); Muniz (2016); Sales Junior (2006); Ferreira (2012); Nascimento (2019); Almeida (2019), entre tantas/os mais.

Destaco também Antônio Bispo dos Santos, um exemplo de pensador quilombola, ativista político e militante na luta pela terra, que tem produzido conhecimento sobre o seu povo e a partir da cosmovisão deles. É o que o autor tem chamado de contra colonização pensando nos processos "de enfrentamento entre povos, raças e etnias em confronto direto no mesmo espaço físico geográfico" (SANTOS, 2015, p. 20).

Da mesma forma, outras intelectuais pertencentes a grupos historicamente subalternizados, como quilombolas, indígenas ou negros, têm ocupado o espaço acadêmico e produzido conhecimento científico a partir da visão dupla de pesquisador/a e sujeito, como Marta Quintiliano e Letícia Jôkàhkwyj Krahô, intelectuais mestras em antropologia social pela Universidade Federal de Goiás. Elas desestabilizam a noção de objeto de pesquisa e reivindicam a produção do conhecimento sobre o próprio povo, questionando a visão de fora do antropólogo branco, que se baseia em teorias hegemônicas vindas da Europa ou dos Estados Unidos. Além disso, desestabilizam ideologias linguísticas que subalternizam povos indígenas e quilombolas ao passo que dominam os códigos impostos pela academia, mas valorizam os modos de produzir conhecimento de seu povo, inclusive por meio da oralidade.

Como argumenta Gonzalez (1983), as mulheres negras têm a necessidade de fazerem suas próprias reflexões ao invés de ficarem presas a modelos prontos de cientistas sociais. Para ela, as pessoas negras têm sido historicamente infantilizadas e privadas da fala, de modo que são sempre usadas como objetos de pesquisa, no entanto, elas têm assumido sua própria fala podendo contar e analisar sua história sob sua própria perspectiva. Por isso, é importante falar de lugares específicos e ressignificar a linguagem, inclusive a acadêmica e científica.

Quintiliano (2019), em sua dissertação de mestrado se apresenta como quilombola antropóloga. A pesquisadora desestabiliza esses lugares argumentando como a antropologia, que se colocou como um campo de estudos sobre o "outro", muitas vezes se utilizou de conhecimentos de povos indígenas e quilombolas como uma forma de objetificação de corpos, utilizando de processos de observação e escuta semelhantes aos das comunidades, com a diferença do registro escrito, que o torna um conhecimento legitimado do ponto de vista eurocêntrico em detrimento do conhecimento transmitido via memória e oralidade nas comunidades.

Para a autora, as pesquisas acadêmicas muitas vezes tratam seus participantes de pesquisa como objetos: "o que lemos na maioria dos casos enquanto pesquisa ainda é a objetificação dos corpos, a desumanização do sujeito das comunidades tradicionais, e na maioria das vezes, a usurpação dos saberes que, ao chegarem à Academia, tornam-se ciência do "branco" ou folclore" (QUINTILIANO, 2019, p. 13).

Além disso, a autora se alia a outras intelectuais, indígenas e quilombolas, para desestabilizar essa forma de conhecimento estabelecida de forma eurocêntrica, imposta pela hegemonia branca no espaço acadêmico:

Ao chegarmos nesse espaço acadêmico, propomos dinâmicas distintas. Letícia Jôkàhkwyj Krahô, indígena, mestranda em antropologia social da Universidade Federal de Goiás (UFG), por exemplo, propõe a inversão da situação assimétrica exposta, e diz que "a universidade, é o seu campo de pesquisa. O estranho está do lado de cá". Muitas vezes, porém, nos decepcionamos ao perceber que os rituais da academia em nada se assemelham aos nossos. De toda forma, precisamos entender como esta estrutura funciona (QUINTILIANO, 2019, p. 13). 
Conforme bell hooks, a linguagem tem um importante papel nas relações de poder, sobretudo nas hierarquias raciais. Para ela, ressignificar os usos linguísticos é uma estratégia de emancipação das pessoas oprimidas. Renomear é um ato decolonial (HELLER, 2017; hooks, 2008). Usar a língua como estratégia de descolonização, pois não é a língua que fere, "mas o que os opressores fazem com ela, como eles a moldam para se tornar um território que limita e define, como eles fazem dela uma arma que pode envergonhar, humilhar, colonizar." (hooks, 2008, p. 858)

Por fim, não podemos deixar de mencionar os conhecimentos que são produzidos fora dos muros da academia, pois diferentes grupos lidam de maneira diferente com a produção do conhecimento, a exemplo dos povos quilombolas e indígenas, como nos mostra Luciano (2017). É muito importante valorizar também essas formas de conhecimento e trazê-las para um diálogo pluridiverso com a academia.

\section{APONTAMENTOS FINAIS}

Para finalizar essa exposição, não posso deixar de observar que não estou no mesmo lugar social que as pesquisadoras negras, quilombolas e indígenas a que faço referência neste artigo, pois a cor da minha pele me deu privilégios diversos, inclusive de acesso aos espaços acadêmicos. Contudo, acredito me aproximar de muitas dessas intelectuais pela identificação do gênero, como mulheres, pela ligação com a academia e com a pesquisa de temas sociais que foram muitas vezes relegados a posições de inferioridade, e pela empatia proporcionada pela luta antirracista.

Por isso, é fundamental refletir sobre o lugar que ocupo na sociedade, como maneira de pensar as relações raciais, problematizando também a branquitude, reconhecendo-me como um corpo racializado nessa sociedade que tende a considerar os corpos brancos como neutros e destituídos de raça. Considero importante que cada vez mais pesquisadoras e pesquisadores se aliem às causas antirracistas, aprendendo a ouvir e a dialogar com toda a diversidade de corpos que finalmente começa a ocupar os espaços historicamente negados.

Isto posto, busquei discutir neste artigo como a colonialidade do poder molda as sociedades no mundo moderno colonial, de maneira a excluir corpos e suas existências linguísticas, perpetuando desigualdades e assimetrias de poder, por meio inclusive de discursos científicos que foram moldados de forma a propagar ideologias linguísticas e sociais que atendem a um projeto de nação hegemônico.

Portanto, apresentei definições de ideologias linguísticas, me alinhando às noções que consideram a dimensão sociocultural e a capacidade dessas racionalizações de moldarem os usos, sendo que elas nunca são neutras. Em seguida, discuti em diálogo, com autoras e autores, como as ideologias linguísticas têm sido usadas para justificar e manter hierarquias, sobretudo as raciais, relacionando as concepções de língua com a diferença colonial. Por fim, apontei como a insurgência das vozes dissidentes tem contribuído para desestabilizar a natureza racializada das ideologias linguísticas e a natureza linguística das ideologias racistas advindas da Modernidade.

\section{REFERÊNCIAS}

ADICHIE, C. N. (2019). O perigo de uma bistória única. Tradução: Julia Romeu. São Paulo: Companhia das Letras.

ALMEIDA, S. (2019). O que é racismo estrutural. Belo Horizonte: Letramento.

ARAÚJO, M. C. S.; MUNIZ, K. (2016). Linguagens, Identidades e Grupos Afroculturais de Minas Gerais: a Problemática da Nomeação. Revista do Programa de Pós-Graduação em Linguística Aplicada da UECE, v. 8, n. 2 - Volume Temático: Linguagem e Raça: diálogos possíveis. p. 23-39.

BAKHTIN, M. (V. N. Volochínov). (1981). Marxismo e filosofia da linguagem. Problemas fundamentais do método sociológico na ciência da linguagem. Trad. Michel Lahud e Yara Frateschi Vieira com a colaboração de Lúcia Teixeira Wisnik e Carlos Henrique D. Chagas Cruz. 2 ed. São Paulo: Hucitec.

BAUMAN, R.; BRIGGS, C. (2000). Language Philosophy and Language Ideology: John Locke and Johan Gottfried Herder. In: Kroskrity, P. V. (org.). Regimes of Language: ideologies, polities, and identities. Santa Fe, New Mexico: School of American Research Press, p. 139-204.

BISPO DOS SANTOS, A. (2015). Colonização, Quilombos: modos e significações. Brasília: INCTI/UNB. 
BLOMMAERT, J.; VERSCHUEREN, J. (1998). The role of language in European Nationalist ideologies. In: Schieffelin, B.; Woolard, K. A.; Kroskrity, P. V. (org.). Language Ideologies: practice and theory. New York/Oxford: Oxford University Press, p. 189-210.

BLOMMAERT, J. (2010). The Sociolinguistics of Globalization. Cambridge: University Press.

BLOMMAERT, J. (2012). Chronicles of complexity. Tilburg Papers in Culture Studies, Tilburg University, n. 29.

BLOMMAERT, J. (2006). Language Ideology. In: Brown, K. (org.). Encyclopedia of Language \& Linguistics, vol. 6, p. $510-522$.

BLOMMAERT, J. (2014). Ideologias linguísticas e poder. Tradução. Ive Brunelli. In: Silva, D. N.; Ferreira, D. M. M.; Alencar, C. N. Nova Pragmática: modos de fazer. São Paulo: Cortez, p. 67-77.

BORBA, R.; LOPES, A. C. (2018). Escrituras de gênero e políticas de différance: imundície verbal e letramentos de intervenção no cotidiano escolar. Linguagem \& Ensino, Pelotas, v. 1, n. esp., VIII SENALE, p. 241-285.

BRAH, Avtar. (1996). Diferença, diversidade, diferenciação. Cadernos Pagu, n. 26, 2006, p. 329-376.

BRASIL. Presidente (2018 - : Jair Messias Bolsonaro). (2019). Discurso do Presidente da República, Jair Bolsonaro, durante a Marcha para Jesus pela Família e pelo Brasil - Brasília/DF. Haia. 10 ago. 2019. Disponível em: https://www.gov.br/planalto/pt-br/ acompanhe-o-planalto/discursos/2019/discurso-do-presidente-da-republica-jair-bolsonaro-durante-a-marcha-parajesus-pela-familia-e-pelo-brasil-brasilia-df\#: :text=O\%20Estado\%20\%C3\%A9\%20laico\%2C\%20mas,do\%20povo\%20 brasileiro\%20\%C3\%A9\%20crist\%C3\%A3o. Acesso em: 10 mar. 2021.

FANON, F. (2008). Pele negra, máscaras brancas. Salvador: Edufba.

FERREIRA, A. J. (2012). Identidades Sociais, Letramento Visual e Letramento Crítico: imagens na mídia acerca de raça/etnia. Trab. Ling. Aplic., Campinas, n. 51 v. 1, p. 193-215, jan./jun. 2012.

G1. (2019). Homem morre após ser baleado em ação do Exército na Zona Oeste do Rio. Disponível em: https://g1.globo.com/rj/rio-de-janeiro/ noticia/2019/04/07/homem-morre-apos-carro-ser-atingido-em-acao-do-exercito-na-zona-oeste-do-rio.ghtml Acesso em: 16 jul. 2019.

GONZALEZ, L. (1983). Racismo e sexismo na cultura brasileira. Ciências sociais boje. Brasília: ANPOCS, n. 2, p. $223-244$.

HELLER, M.; McELHINNY; B. (2017). Language in Late Capitalism: Intensifications, unruly desires, and alternative worlds. In: Heller, M.; Mcelhinny; B. Language, capitalism, colonialism: toward a critical history. Toronto: University of Toronto Press, p. $227-260$.

hooks, bell. (1994). Linguagem: ensinar novas paisagens/novas linguagens. Revista Estudos Feministas, Florianópolis, v. 6, n. 3, 2008, p. $857-864$.

IRVINE, J. T. (1989). When talk isn't cheap: language and political economy. American Etbnologist, v. 16, n. 2, p. $248-267$.

KRAHÔ, L. J. (2019). Pjê Ita jê kâm mã itê ampô kwy jakrepej: das possibilidades das narrativas na educação escolar do povo Krahô. Dissertação de Mestrado em Antropologia Social. Faculdade de Ciências Sociais, Universidade Federal de Goiás, Goiânia.

KROSKRITY, P. V. (2004). Language Ideologies. In: Duranti, A. (org.). A companion to Linguistic Anthropology. Oxford: Blackwell Publishing, p. 496-517.

LIMA, Fernanda da Silva; SILVA, Karine de Souza. TEORIAS CRÍTICAS E ESTUDOS PÓS E DECOLONIAIS À BRASILEIRA: QUANDO A BRANQUITUDE ACADÊMICA SILENCIA RAÇA E GÊNERO. Coluna Empório Descolonial. 2020. Disponível em: https://emporiododireito.com.br/leitura/teorias-criticas-e-estudos-pos-e-decoloniaisa-brasileira-quando-a-branquitude-academica-silencia-raca-e-genero\#.XvP0qBKU7EE.whatsapp

LUCIANO, G. J. dos S. (2017). Língua, educação e interculturalidade na perspectiva indígena. Revista de Educação Pública, [S. l.], v. 26, n. 62/1, p. 295-310. DOI: 10.29286/rep.v26i62/1.4996. Disponível em: https://periodicoscientificos.ufmt.br/ojs/ index.php/educacaopublica/article/view/4996. Acesso em: 4 mar. 2021. 
LUGONES, M. (2010). Rumo a um feminismo descolonial. Estudos Feministas, Florianópolis, v. 22, n. 3, setembro-dezembro/2014, p. $935-952$.

MIGNOLO, W. (2003). Histórias locais / projetos globais: colonialidade, saberes subalternos e pensamento liminar. Belo Horizonte: Editora UFMG.

MILROY, J. (2011). Ideologias Linguísticas e as consequências da padronização. Trad. Marcos Bagno. In: Lagares, X. C.; Bagno, M. (org.). Políticas da norma e conflitos linguísticos. São Paulo: Parábola, p. 49-87.

MUNIZ, K. (2016). Ainda sobre a possibilidade de uma linguística "crítica": performatividade, política e identificação racial no Brasil. D.E.L.T.A., v. 32, n. 3, p. 767-786.

NASCIMENTO, G. (2019). Racismo linguístico: os subterrâneos da linguagem. Belo Horizonte: Letramento.

OLIVEIRA, D. P. (2018). Ideologias de linguagem acionadas por docentes indígenas em formação superior: tensões no espaço da diferença colonial. Dissertação de Mestrado em Letras e Linguística. Faculdade de Letras, Universidade Federal de Goiás. Goiânia.

OSÓRIO, R. G. (2003). O sistema classificatório de "cor ou raça" do IBGE. Brasília: IPEA.

PINTO, J. P. (2014). Contradições e Hierarquias nas Ideologias Linguísticas do Conselho Nacional de Imigração. Domínios de lingu@gem.v.8,n.3,p.108-134.

PINTO, J. P. (2015). De diferenças e hierarquias no quadro Adelaide às análises situadas e críticas na Linguística Aplicada. DELTA. Documentação de Estudos em Linguística Teórica e Aplicada, v. 31, p. 199-221.

PINTO. J. P. (2018). Ideologias Linguísticas e a Instituição de Hierarquias Raciais. Revista da ABPN. v. 10, ed. Especial - Caderno Temático: Letramentos de Reexistência, p.704-720.

QUINTILIANO, M. (2019). Redes Afro-Indígenoafetivas: uma Autoetnografia sobre Trajetórias, Relações e Tensões entre Cotistas da Pós-Graduação Stricto Sensu e Políticas de Ações Afirmativas na Universidade Federal De Goiás. Dissertação de Mestrado em Antropologia Social. Faculdade de Ciências Sociais, Universidade Federal de Goiás, Goiânia.

ROSA, J.; FLORES, N. (2017). Unsettling race and language: Toward a raciolinguistic perspective. Language and Society, v. 46, n. 5, p. 621-647.

ROSA, J. (2019). Looking like a language, sounding like a race: raciolinguistic ideologies and the learning of Latinidad. New York: Oxford University Press, p. 125-176.

SALES JUNIOR, R. (2006). Democracia racial: o não-dito racista. Tempo Social, revista de sociologia da USP. v. 18, n. 2, p. $229-258$.

SIGNORINI, I. (2008). Metapragmáticas da língua em uso: unidades e níveis de análise. In: Signorini, I. (org.). Situar a lingua(gem). São Paulo: Parábola Editorial, p. 117-148.

SILVERSTEIN, M. (1979). Language Structure and Linguistic Ideology. In: Clyne, P. R.; Hanks, W. F.; Hofbauer, C. L. (org.). The Elements: a parasession on linguistic units and levels. Chicago: Chicago Linguistic Society, p. 193-247.

WALLERSTEIN, I. (1974). The Modern World-System: Capitalist Agriculture and the Oringins of the European World-Economy in the Sixteenth Century. New York: Academic Press.

WOOLARD, K. (1998). Introduction: language ideology as a field of inquiry. In: Schieffelin, B.; Woolard, K. A.; Kroskrity, P. V. (org.). Language Ideologies: practice and theory. New York/Oxford: Oxford University Press, p. 3-47.

Recebido: 30/10/2020

Aceito: 3/3/2021

Publicado: 22/3/2021 